\title{
Influência da suplementação no pré-parto e da idade de desmama sobre o desempenho de cordeiros terminados em confinamento ${ }^{1}$
}

\author{
Gilberto Teixeira da Rosa², Edson Ramos de Siqueira ${ }^{3}$, Sarita Bonagurio Gallo4, \\ Sofia Simões Silveira Moraes ${ }^{5}$
}

\author{
${ }^{1}$ Parte da tese de Doutorado do primeiro autor. Projeto financiado pela FAPESP. \\ 2 In memoriam. \\ ${ }^{3}$ FMVZ, UNESP, 18600-000, Botucatu, SP \\ ${ }^{4}$ FAZU, Uberaba, MG. \\ ${ }^{5}$ Graduando em Zootecnia, da Faculdade de Medicina Veterinária e Zootecnia da UNESP, Botucatu-SP
}

RESUMO - Objetivou-se avaliar o efeito da suplementação no pré-parto e da idade à desmama sobre o desempenho de cordeiros terminados em confinamento. Foram utilizadas 44 matrizes mestiças Ile de France $\times$ Bergamácia acasaladas com cordeiro Ile de France mantidas em pastagem de Panicum maximum cv. Tanzânia, em sistema de pastejo rotacionado, até 30 dias antes do parto, quando foram separadas em dois grupos. No pré-parto, apenas o primeiro grupo (SUPL) recebeu suplementação (1\% peso vivo) com dieta balanceada. Após o parto, ambos os grupos, com (SUPL) e sem suplementação (NS), receberam suplementação. Por sorteio, metade dos cordeiros de cada grupo foi desmamada aos 45 dias e a outra metade, aos 60 dias de idade. Após a desmama, os cordeiros foram mantidos em confinamento com dieta balanceada e abatidos aos $30 \mathrm{~kg}$ de PV, após jejum de sólidos de 16 horas. O peso e a condição corporal ao parto das ovelhas diferiram entre os grupos, o que não ocorreu ao desmame. Os peso ao nascimento e ao desmame, o ganho de peso do nascimento ao desmame e do desmame ao abate, o período em confinamento e a idade ao abate não diferiram entre os cordeiros. O peso ao desmame e o ganho de peso do desmame ao abate foram influenciados pela idade à desmama (os cordeiros apresentaram 0,20 kg aos 45 dias e $0,15 \mathrm{~kg}$ aos 60 dias de idade). A suplementação proporcionou melhor condição corporal às ovelhas e a desmama aos 45 dias promoveu melhor desempenho aos cordeiros.

Palavras-chave: condição corporal, desmama, ganho de peso, ovino

\section{Effect of ewe pre-partum supplementation and weaning age on performance of feedlot finished lambs}

\begin{abstract}
The objective of this trial was to evaluate the effect of ewe pre-partum supplementation and weaning age on performance of lambs. Forth-four Ile de France x Bergamasca ewes that were mated with Ile de France rams were used in this trial. Animals were maintained in a rotational grazing system of Panicum maximum (cv. Tanzânia) pasture until 30 days before parturition. Ewes were then divided in two groups: supplemented (SUPL) and not-supplemented (NS); animals on the SUPL group were supplemented (1\% of body weight [BW]) with a balanced diet according to NRC (1985) requirements. After parturition, both groups were supplemented. Half of lambs from the SUPL and NS groups were weaned at 45 days of age and the other half at 60 days of age. After weaning lambs were feedlot fed with a diet balanced according to NRC (1985) model. Lambs were slaughtered when they reached $30 \mathrm{~kg}$ of BW after 16 hours of solids fasting. Both BW and body condition score of ewes at parturition differed between SUPL and NS groups while the same was not observed at weaning. Birth weight, weaning weight, weight gain from birth to weaning and from weaning to slaughter, days in feedlot, and slaughter age all were not different in lambs born from ewes of the SUPL or NS groups. However, significant differences were observed for weaning weight and weight gain from weaning to slaughter between groups of animals weaned at 45 or 60 days of age.
\end{abstract}

Key Words: body condition, sheep, weaning, weight gain

\section{Introdução}

A produção de carne de cordeiros é uma possibilidade de renda para o produtor se considerado o grande potencial de crescimento do setor (Garcia et al., 2000), mas, para que seja viável, é necessária a correta utilização dos manejos reprodutivos, sanitários e nutricionais.

Os ovinos são ruminantes com alta capacidade para se alimentarem exclusivamente de pastagem e produzirem proteína de alto valor biológico. No entanto, a produção desses 
animais depende da disponibilidade cíclica de forragem, que, na época da seca, pode apresentar qualidade inferior e baixo suporte nutricional às ovelhas, principalmente as gestantes. Uma solução eficaz seria o fornecimento de suplemento alimentar às ovelhas no terço final da gestação e durante a lactação, que, segundo Montossi et al. (1998), é um período importante, pois corresponde ao maior crescimento do feto, ao desenvolvimento do úbere e à sua capacidade de produzir colostro e leite.

Bento et al. (1981) estudaram grupos de ovelhas mantidos exclusivamente em pastagem nativa (PN) ou em pastagem nativa com acesso à pastagem de azevém durante 3 horas/dia e suplementação de 500 g de resíduo de soja misturado com 100 gramas de palha de soja triturada (PNS). Esses autores verificaram que a condição corporal superior das ovelhas sob suplementação com PNS no final da gestação proporcionou maior vigor aos cordeiros ao nascimento e resultou em altos índices de sobrevivência, principalmente nas primeiras horas de vida.

O desmame precoce e a terminação de cordeiros em confinamento têm despertado o interesse de ovinocultores, pois constituem formas de aumentar a produção de cordeiros para o abate. $\mathrm{O}$ peso do cordeiro ao nascimento e à desmama está intimamente relacionado à taxa de sobrevivência e ao histórico nutricional da ovelha durante os períodos de gestação e lactação. O alto peso da desmama diminui o período de confinamento do cordeiro. Siqueira (2000) afirmou que um cordeiro para confinamento deve apresentar as seguintes características: boa conversão alimentar, altas taxas de ganho de peso e adequada deposição de gordura. Para atingir esses objetivos, deve-se planejar corretamente o sistema de produção, integrando harmonicamente a genética, a alimentação e o manejo.

Um dos problemas sanitários da criação é a verminose, que pode resultar em elevadas taxas de mortalidade. Algumas técnicas são recomendadas para minimizar esse problema, entre elas, a desmama precoce e o confinamento total dos cordeiros (Siqueira et al., 1993). A técnica de desmame precoce é amplamente recomendada por diversos pesquisadores (Carvalho, 1998; Silva, 1999; Motta, 2000; Vilas Boas, 2001) e constitui-se em um aproveitamento racional do pico de lactação, acrescido à utilização de alimentos complementares.

Objetivou-se com este estudo avaliar o efeito da suplementação no pré-parto e da idade à desmama sobre o desempenho de cordeiros terminados em confinamento.

\section{Material e Métodos}

O experimento foi realizado na Faculdade de Medicina Veterinária e Zootecnia, UNESP, campus de Botucatu, SP.

Foram utilizadas 44 ovelhas prenhes adultas Ile de France $\times$ Bergamácia acasaladas com um cordeiro Ile de France. Todas as matrizes permaneceram em pastagens de Panicum maximum cv. Tanzânia, em sistema de pastejo rotacionado, até 30 dias antes do parto, quando foram separadas em dois grupos de 22 fêmeas. O primeiro grupo foi mantido na pastagem de Panicumm maximum cv. Tanzânia e recebeu suplementação (SUPL) com concentrado (Tabela 1), ingerindo nutrientes (pastagem mais concentrado) suficientes para atender às exigências descritas pelo NRC (1985). O segundo grupo (NS) permaneceu na pastagem, mas não recebeu suplementação. Após o parto, todas as ovelhas que pariram macho, de ambos os grupos (SUPL e NS), receberam, cada uma, suplementação com 1 kg de concentrado (Tabela 1).

As infestações endoparasitárias foram monitoradas a cada 15 dias por meio da coleta de amostras de fezes, diretamente na ampola retal, em 30\% das ovelhas escolhidas aleatoriamente. Os exames de fezes foram realizados pela técnica de Gordon \& Whitlock (1939). Médias de OPG (ovos por grama de fezes) superiores a 500 denotaram necessidade de everminação.

As ovelhas e os cordeiros foram pesados a intervalos de 14 dias do parto até o desmame. Foram realizadas avaliações da condição corporal das ovelhas no início do experimento, 24 horas após o parto e a cada 14 dias até o momento do desmame. A condição corporal foi avaliada atribuindo-se notas de 1 a 5 (1 para animais muito magros e 5 para obesos, com intervalos de 0,25), conforme Sañudo \& Sierra (1993). Os escores de condição corporal foram obtidos pela palpação dos processos dorsais e transversos das vértebras lombares, avaliando-se a quantidade de músculo e de gordura no ângulo formado por esses dois processos.

Por sorteio, metade dos cordeiros de cada grupo foi desmamada aos 45 dias e a outra metade, aos 60 dias. Todos os cordeiros foram vacinados contra carbúnculo sintomático, gangrena gasosa e enterotoxemia 15 dias antes do desmame (reforço após 15 dias). No momento do desmame, foram pesados, identificados, everminados e distribuídos aleatoriamente em quatro tratamentos: cordeiros filhos de ovelhas submetidas à suplementação pré-parto e desmamados aos 45 dias $(n=5)$ ou aos 60 dias de idade $(n=6)$; cordeiros filhos de ovelhas mantidas em pastagem sem suplementação e desmamados aos 45 dias $(n=6)$ ou aos 60 dias de idade $(n=5)$. 
Os animais foram confinados em baias coletivas cobertas, com piso de concreto, com cocho e bebedouro. Os cordeiros tiveram livre acesso a água limpa e sal mineral e receberem alimento à vontade, em quantidade calculada para proporcionar ganho médio diário de 0,300 kg (NRC, 1985).

O volumoso foi constituído de feno de Panicum Maximum cv. Aruana moído e o concentrado, de mistura comercial para ovinos de engorda contendo farelo de trigo, remoído de trigo, uréia pecuária, promotor de crescimento, caulim, calcário calcítico, cloreto de sódio (sal comum), melaço, premix mineral, premix vitamínico e gérmen de milho (Tabela 1). Os animais foram alimentados uma vez ao dia e o ajuste das quantidades de alimento foi feito considerando a sobra do dia anterior (no máximo 20\% da quantidade oferecida), de modo a garantir o consumo voluntário dos animais. Registraram-se diariamente a quantidade de alimento oferecido e a de sobras por baia.

As pesagens intermediárias dos animais em confinamento foram realizadas sem jejum prévio, em intervalos de 14 dias, reduzido para sete dias à medida que o peso dos cordeiros se aproximou do peso de abate. Ao atingirem $30 \mathrm{~kg}$ de PV, os cordeiros foram pesados antes (peso na origem) e após jejum de sólidos de 16 horas, para registro do peso de abate e, em seguida, foram sacrificados. Os cordeiros não foram castrados e, ao abate, apresentavam em média 107 dias (desmamados com 45 dias) e 111 dias de idade (desmamados com 60 dias) (Tabela 3).

Foram avaliados nas ovelhas os pesos e as condições corporais ao parto e ao desmame e, nos cordeiros, os pesos ao nascimento e ao desmame, os ganhos de peso do nascimento ao desmame e do desmame ao abate, o período em confinamento, a idade ao abate, o consumo de MS e a conversão alimentar. O consumo de MS foi calculado por baia e permitiu estimar a conversão alimentar e o consumo individual médio em valores absolutos.

Tabela 1 - Composição bromatológica (\%) dos alimentos consumidos pelas ovelhas e pelos cordeiros

Table 1 - Chemical composition (\%) of feeds fed to ewes and lambs

\begin{tabular}{lrcrr}
\hline & $\begin{array}{c}\text { Pastagem } \\
\text { Pasture }\end{array}$ & $\begin{array}{c}\text { Concentrado } \\
\text { Concentrate }\end{array}$ & $\begin{array}{c}\text { Feno } \\
\text { Hay }\end{array}$ & $\begin{array}{r}\text { Dieta } \\
\text { completa } \\
\text { Total diet }\end{array}$ \\
\hline MS (DM) & 90,20 & 87 & 88,67 & 89,02 \\
PB (CP) & 5,29 & 18 & 11,42 & 17,42 \\
EE & 1,69 & 1,5 & 1,40 & 4,03 \\
FB (CF) & 34,02 & 17 & 41,86 & 17,54 \\
Cinzas (Ash) & 8,48 & 10 & 9,77 & 8,03 \\
FDN (NDF) & 74,34 & & 75,24 & 48,76 \\
FDA (ADF) & 50,60 & & 55,62 & 23,29 \\
Ca & & 2 & & \\
P & & 0,4 & & \\
\hline
\end{tabular}

Empregou-se o delineamento experimental inteiramente casualizado com arranjo fatorial $2 \times 2$ (dois níveis nutricionais da ovelha e duas idades ao desmame), em um total de quatro tratamentos com cinco e/ou seis repetições, totalizando 22 cordeiros machos não-castrados. Os dados foram submetidos à análise de variância e ao teste F a 5\% de significância e as médias foram comparadas pelo teste t, também a 5\% de significância. Os dados foram analisados pelo procedimento GLM do Sistema de Análise Estatística (SAS, 1999).

\section{Resultados e Discussão}

De acordo com as análises de variância, não houve interação significativa suplementação $\times$ idade ao desmame. Portanto, os resultados são apresentados de forma independente.

O peso (51,58 e 47,91 kg) e a condição corporal (2,50 e 2,16$)$ ao parto diferiram $(\mathrm{P}<0,05)$ entre as ovelhas dos grupos SUPL e NS (Tabela 2). A suplementação e a idade de desmame não influenciaram $(\mathrm{P}>0,05)$ o peso e a condição corporal das ovelhas ao desmame. Os resultados denotam a importância da suplementação nos 30 dias anteriores ao parto, quando as exigências de ovelhas gestantes são altas e não podem ser atendidas pela alimentação exclusivamente em pastagem (Tabela 1). Além disso, nas condições do experimento, a pastagem apresentava concentrações de fibra relativamente altas, o que diminuiu a capacidade de ingestão de MS pela ovelha, provocando deficiência energética no final da prenhez.

As ovelhas do grupo SUPL apresentaram maior peso e melhor condição corporal, pariram e desmamaram cordeiros mais pesados e mantiveram o peso durante a lactação, o que justifica a suplementação. No entanto, verificou-se perda da condição corporal, provavelmente em virtude da oxidação das reservas corporais para produção de leite. Esses resultados estão de acordo com os obtidos por Montossi et al. (1998), que afirmaram que a condição corporal diminui durante a lactação, em decorrência da mobilização das reservas corporais para suprimento de determinadas carências energéticas provocadas pelo desbalanço entre o requerimento e a capacidade de ingestão.

O peso das ovelhas do grupo NS aumentou após o parto como resultado da maior síntese de proteína microbiana estimulada pela ingestão de concentrado, que proporcionou maior digestão da forragem ingerida (Orskov, 1988), resultando em ganho compensatório. Ressalta-se que as ovelhas receberam a mesma dieta durante a lactação e, em termos percentuais, as do grupo SUPL tiveram maior perda da condição corporal (19,3\%) em comparação às do grupo NS (13,9\%). 
Tabela 2 - Peso e condição corporal de ovelhas submetidas (SUPL) ou não (NS) à suplementação alimentar no pré-parto e peso dos cordeiros ao nascimento

Table 2 - Body weight and body condition score of supplemented (SUPL) and not-supplemented (NS) ewes before lambing and lamb weight at birth

\begin{tabular}{lccc}
\hline $\begin{array}{l}\text { Variável } \\
\text { Item }\end{array}$ & \multicolumn{2}{c}{$\begin{array}{c}\text { Tratamento } \\
\text { Treatment }\end{array}$} & \multirow{2}{*}{ CV \% } \\
\cline { 2 - 3 } & SUPL & NS & \\
\hline $\begin{array}{l}\text { Peso da ovelha ao parto (kg) } \\
\text { Weight of ewes at lambing }\end{array}$ & $51,58^{\mathrm{a}}$ & $47,91^{\mathrm{b}}$ & 13,41 \\
$\begin{array}{l}\text { Peso da ovelha ao desmame (kg) } \\
\text { Weight of ewes at weaning }\end{array}$ & 51,45 & 50,61 & 10,92 \\
$\begin{array}{l}\text { Condição corporal ao parto } \\
\text { Body condition score at lambing }\end{array}$ & $2,50^{\mathrm{a}}$ & $2,16^{\mathrm{b}}$ & 27,86 \\
$\begin{array}{l}\text { Condição corporal ao desmame } \\
\text { Body condition score at weaning }\end{array}$ & 2,05 & 1,81 & 23,37 \\
$\begin{array}{l}\text { Peso ao nascimento (kg) } \\
\text { Birth weight }\end{array}$ & 5,47 & 4,97 & 11,69 \\
\hline
\end{tabular}

Médias seguidas de letras distintas na linha diferem $(P<0,05)$ a $5 \%$ de probabilidade pelo teste $t$.

Means followed by different letters within a row differ $(P<0.05)$ at $5 \%$ of probability by t test.

Resultados semelhantes foram observados por Boucinhas (2004), que estudou a influência da suplementação alimentar no terço final da gestação e verificou que as ovelhas submetidas à suplementação tiveram maiores pesos ao parto e ao desmame, com condição corporal superior ao parto e semelhante ao desmame. Pires et al. (2000) observaram que, no período de aleitamento, as ovelhas que não receberam suplementação antes do parto perderam em média 5,33\% do peso após o parto, correspondente a uma perda de $-0,056 \mathrm{~kg} / \mathrm{dia}$. A manutenção de peso das matrizes durante a lactação possibilitaria a utilização de sistemas mais intensivos, como três partos a cada dois anos.

$\mathrm{O}$ peso dos cordeiros ao nascimento (PN) não foi influenciado $(\mathrm{P}>0,05)$ pela suplementação no pré-parto (5,47 kg com suplementação e 4,97 kg sem suplementação). A diferença de peso, apesar de não-significativa (499 g a mais para cordeiros filhos de ovelhas que receberam suplemento), pode ser atribuída à boa condição corporal das ovelhas mantidas sob suplementação no terço final da gestação. Beetson (1984) verificou que cordeiros filhos de ovelhas mantidas sob plano nutricional superior no terço final da gestação foram $170 \mathrm{~g}$ mais pesados. Chestnutt (1989) constatou que ovelhas no terço final da gestação que tiveram maior consumo de MS pariram cordeiros $320 \mathrm{~g}$ mais pesados. Bento et al. (1981), em pesquisa realizada no Rio Grande do Sul com ovelhas da raça Corriedale, também observaram que cordeiros filhos de ovelhas mantidas em pastagem de azevém ou campo nativo com suplementação nasceram 420 e 330 g mais pesados, respectivamente, que os filhos de ovelhas mantidas em campo nativo sem suplementação.

Os dados de peso ao desmame (PD), ganho de peso do nascimento ao desmame (GPND), ganho de peso do desmame ao abate (GPDA), de período em confinamento (CONF) e de idade ao abate (IDB) são descritos na Tabela 3. Não houve efeito da suplementação e da idade de desmame $(\mathrm{P}>0,05)$ sobre nenhuma das característica de desempenho estudadas.

O peso ao desmame depende da produção de leite das ovelhas e da disponibilidade de alimentos sólidos aos cordeiros. Após o desmame, o ganho de peso depende principalmente da adaptação dos animais aos alimentos sólidos e da qualidade da dieta. Os resultados obtidos para idade ao desmame (45 ou 60 dias) comprovaram diferença $(\mathrm{P}<0,05)$ para peso ao desmame $(19,00$ e 23,30 kg) e GPDA $(0,20$ e 0,15 kg), mas não houve diferença $(P>0,05)$ para GPND, CONF e ID. Os cordeiros desmamados aos 60 dias de idade foram mais pesados, porém, apresentaram pior desempenho na terminação, mesmo período em confinamento e mesma idade ao abate, mas essa diferença no peso ao desmame foi ocasionada pela idade, e não pelo ganho de peso diário, que foi menor no intervalo de 45 a 60 dias.

Pilar et al. (1994) citaram que o fato de o cordeiro permanecer mais tempo com a mãe os expõe a maior infestação parasitária, que pode ser prejudicial ao seu desenvolvimento e, portanto, o desmame precoce pode ser uma estratégia para minimizar este problema. Silva (1999) registrou peso médio ao desmame (aos 45 dias) de 19,94 kg para

Tabela 3 - Peso ao desmame (PD), ganho de peso do nascimento ao desmame (GPND), ganho de peso do desmame ao abate (GPDA), dias em confinamento (CONF) e idade ao abate (ID) de cordeiros filhos de ovelhas submetidas (SUPL) ou não (NS) à suplementação pré-parto desmamados aos 45 ou aos 60 dias de idade

Table 3 - Means and coefficient of variation for body weight at weaning (BWW), weight gain from birth to weaning (WGBW), weight gain from weaning to slaughter (WGWS), days in feedlot (DF) and age (AGE) of lambs born from ewes supplemented (SUPL) or not supplemented (NS) before lambing and weaned at 45 or 60 days of age

\begin{tabular}{lccccc}
\hline Tratamento & PD (kg) & GPND (kg) GPDA (kg) & CONF & ID \\
Treatment & $B W W$ & $W G B W$ & $W G W S$ & $D F$ & $A G E$ \\
\hline SUPL & 20,90 & 0,30 & 0,19 & 57,76 & 110 \\
NS & 21,40 & 0,30 & 0,16 & 67,43 & 108 \\
45 dias & $19,00^{\mathrm{a}}$ & 0,30 & $0,20^{\mathrm{a}}$ & 62,76 & 107 \\
45 days & & & & & \\
60 dias & $23,30^{\mathrm{b}}$ & 0,29 & $0,15^{\mathrm{b}}$ & 62,43 & 111 \\
60 days & & & & & \\
CV\% & 15,09 & 18,24 & 18,43 & 25,29 & 12,34 \\
\hline
\end{tabular}

Médias seguidas de letras distintas na coluna, dentro do mesmo tratamento, diferem $(P<0,05)$ pelo teste $t$.

Means followed by different letters, within a column, differ $(P<0.05)$ by t test. 
cordeiros não-castrados mestiços Texel $\times$ Ideal. Esse autor considera que o peso ao desmame depende principalmente da produção de leite da ovelha e da disponibilidade de alimentos sólidos aos cordeiros. Maestá (2003), em experimento com ovelhas alimentadas segundo recomendações do NRC (1985) com dietas contendo valores de PB e NDT $20 \%$ superiores ao recomendado e com ovelhas alimentadas apenas com feno de coastcross, observou que cordeiros filhos de ovelhas alimentadas apenas com feno apresentaram ganhos diários menores $(\mathrm{P}<0,05)$, de $0,18 \times 0,34 \mathrm{~kg}$ para os demais. Verificou ainda efeito dos tratamentos $(\mathrm{P}<0,05)$ sobre o peso ao desmame, pois os cordeiros filhos de ovelhas alimentadas apenas com feno apresentaram menores pesos ao desmame $(14,40 \times 25,26 \mathrm{~kg}$ para os demais).

Estudando o ganho de peso de cordeiros Hampshire Down desmamados aos 34 e aos 62 dias de idade com acesso a comedouro privativo filhos de ovelhas mantidas em pastagem nativa com ou sem suplementação com concentrado (1\% do PV), Vilas Bôas (2001) observou que os cordeiros desmamados aos 62 dias apresentaram ganho de peso superior ao dos desmamados aos 34 dias. $O$ peso à desmama aos 62 dias foi maior nos cordeiros filhos de mães que não receberam suplementação $(\mathrm{P}<0,05)$ - esses animais foram abatidos em idade mais precoce se comparados aos filhos de ovelhas submetidas à suplementação. No experimento realizado por esse autor, a suplementação pós-desmame influenciou o ganho de peso diário dos cordeiros, independentemente da idade ao desmame.

Os resultados obtidos neste estudo comprovaram maior velocidade de ganho do nascimento ao desmame (média de 0,305 kg). A partir do desmame, observou-se acentuada diminuição do ganho de peso diário (GPDA). A velocidade de crescimento (GPDA) foi maior nos cordeiros desmamados aos 45 dias de idade, provavelmente em virtude da maior dependência de leite dos cordeiros desmamados aos 60 dias, o que acarretou maior estresse pela mudança abrupta de uma dieta semilíquida para uma exclusivamente sólida. Além disso, como permaneceram mais tempo na pastagem, o aumento da ingestão de matéria seca da pastagem pode ter ocasionado problemas sanitários e prejuízos no desempenho à terminação. Mesmo assim, esses animais permaneceram o mesmo período no confinamento, se comparados aos desmamados aos 45 dias, e foram abatidos com apenas mias quatro dias de idade.

Na avaliação de desempenho de cordeiros Morada Nova castrados com peso vivo médio de 19,68 kg confinados e alimentados com níveis crescentes de concentrado (20, 40, 60 e $80 \%$ na dieta), Medeiros et al. (2004) registraram ganhos médios diários de 0,089; 0,134; 0,168 e 0,224 kg, respectivamente, correspondentes a 35,6; 53,6; 67,2 e 89,6\% do ganho de peso de $0,250 \mathrm{~kg} /$ dia preconizado pelo NRC (1985). Neste estudo, o concentrado foi fornecido na proporção de 70\% da dieta e possibilitou ganhos de 83,2 e 62\% do preconizado pelo NRC (1985) para cordeiros desmamados aos 45 ou 60 dias de idade, respectivamente.

Otto et al. (1994), ao compararem o efeito da idade ao desmame (de 45 ou 60 dias) no desenvolvimento de cordeiros mestiços Suffolk com acesso a alimentador privativo provido de concentrado com $14 \%$ de PB e $60 \%$ NDT, além de pastagem de inverno, não notaram diferença $(\mathrm{P}>0,50)$ entre os cordeiros até 120 dias de idade e aqueles desmamados aos 45 ou 60 dias (ganho médio diário de 190 e 182 g, respectivamente). Resultados contrários foram citados por Ragland et al. (1988), que avaliaram o desempenho de cordeiros gêmeos em diferentes idades ao desmame e verificaram que cordeiros desmamados em idade mais precoce ganharam 9 a $12 \%$ menos peso e necessitaram de mais tempo para atingirem o peso de abate se comparados aos cordeiros desmamados tardiamente.

Era previsível que o retardamento do desmame em 15 dias, com as ovelhas recebendo suplementação e os cordeiros comendo juntos possibilitaria por mais tempo a utilização do leite como fonte de nutrientes e propiciaria mais tempo para desenvolvimento do trato digestivo dos cordeiros, proporcionando melhor utilização da dieta no confinamento. No entanto, os resultados comprovaram maior velocidade de ganho do nascimento ao desmame, em média $0,30 \mathrm{~kg}$ GPND. Depois do desmame, ocorreu acentuada diminuição do ganho de peso diário (59,90\% do ganho diário obtido no período anterior). Carvalho et al. (1999), em experimento com cordeiros não-castrados confinados e desmamados aos 50 dias, verificaram ganhos de médios diários de 0,316 $\mathrm{kg}$ antes do desmame e de $0,159 \mathrm{~kg}$ após o desmame. Motta (2000), por sua vez, registrou ganhos de 0,299 kg antes e de 0,117 kg após o desmame.

Para cordeiros desmamados aos 45 dias, peso ao nascimento de 5,06 kg representa 16,87\% do peso médio de abate, enquanto o peso ao desmame representa $63,35 \%$. Para cordeiros desmamados aos 60 dias, peso ao nascimento de 5,38 kg representa $18,14 \%$ do peso de abate, enquanto o peso ao desmame corresponde a $80,18 \%$. O tempo médio do desmame ao abate foi de 62,30 dias para ambas as idades de desmame. Esses resultados e os de ganho de peso comprovam que os excelentes resultados obtidos do nascimento ao desmame praticamente se diluíram, como conseqüência do baixo desempenho dos cordeiros após o desmame, mesmo com o fornecimento de uma dieta compatível com as exigências nutricionais da categoria. Os 
resultados indicam ainda que os cordeiros precisam ser mais bem preparados para responderem melhor ao desmame em idade jovem.

Constam na Tabela 4 os resultados obtidos para conversão alimentar (CA), consumo diário de matéria seca (CDMS) e ganho de peso do nascimento ao abate (GPNB). Os animais do grupo NS consumiram a mais 0,100 kgMS por dia, tiveram melhor conversão alimentar com consumo suplementar de 1,023 kgMS/kgPV (15,146\% a mais de MS) e ganho de peso diário de 0,004 kg menor. Apesar de não haver diferença estatística, os cordeiros desmamados aos 45 dias consumiram menos alimento e tiveram melhor conversão alimentar em relação aos cordeiros desmamados com 65 dias (Tabela 4).

Os consumos de MS encontrados foram similares aos verificados por Garcia (2001), de 1,050 kg/animal/dia, em estudo com animais dos 60 aos 135 dias de idade. Pires et al. (2000), no entanto, observaram consumo de MS de 0,686 e $0,712 \mathrm{~kg} / \mathrm{animal} / \mathrm{dia}$ em cordeiros Ideal e cruza (Texel $\times$ Ideal) e conversões alimentares de 4,40 e 4,22 kgMS/kgPV para cordeiros abatidos aos 28 e aos $33 \mathrm{~kg}$ de PV, respectivamente. Carvalho et al. (1999) reportaram consumo médio diário de 0,57 kg de MS para cordeiros dos 50 aos 100 dias de idade, inferior ao observado neste estudo.

Ribeiro (1996) afirmou que a conversão alimentar de cordeiros é de 1 no período inicial de amamentação e pode aumentar para 10 no desmame em pastagens pobres e, na terminação com dieta comercial de má qualidade, pode chegar a 3. Essa afirmativa corrobora os relatos de Orskov (1988), que registrou ganho de 0,35 kg/dia e conversão

Tabela 4 - Consumo diário de MS (CDMS), conversão alimentar (CA) e ganho de peso médio diário do nascimento ao abate (GPNB) de cordeiros filhos de ovelhas submetidas (SUPL) ou não (NS) à suplementação alimentar no pré-parto e desmamados aos 45 ou aos 60 dias de idade

Table 4 - $\quad$ Means for daily DM intake (DMI), feed conversion (FC) and average daily weight gain from birth to slaughter (WGBS) of lambs born from ewes supplemented (SUPL) or not-supplemented (NS) before lambing and weaned at 45 or 60 days of age

\begin{tabular}{lccc}
$\begin{array}{l}\text { Tratamento } \\
\text { Treatment }\end{array}$ & $\begin{array}{c}\text { CDMS }(\mathrm{kg}) \\
D M I(\mathrm{~kg})\end{array}$ & $\begin{array}{c}\text { CA }(\mathrm{kgMS} / \mathrm{kgPV}) \\
F C(\mathrm{~kg} D M / \mathrm{kg} B W)\end{array}$ & $\begin{array}{c}\text { GPNB }(\mathrm{kgPV} / \text { dia }) \\
\text { WGBS }\end{array}(\mathrm{kg} \mathrm{BW/day)}$ \\
\hline SUPL & 0,985 & 5,731 & $0,254^{\mathrm{a}}$ \\
NS & 1,085 & 6,754 & $0,250^{\mathrm{a}}$ \\
45 dias & 1,002 & 5,412 & $0,253^{\mathrm{a}}$ \\
45 days & & & \\
60 dias & 1,068 & 7,072 & $0,251^{\mathrm{a}}$ \\
60 days & & & \\
CV \% & 43,889 & 46,263 & 12,275
\end{tabular}

Médias seguidas de letras distintas na coluna, entre tratamentos, diferem $(\mathrm{P}<0,05)$ pelo teste de Pdiff.

Means followed by different letters, within a column, differ $(P<0.05)$ by t test. alimentar de 3 para cordeiros terminados em confinamento. O índice médio de conversão alimentar de 6,24 foi semelhante ao observado por Pilar et al. (1994), que trabalharam com borregos de 12 meses de idade, de cinco genótipos, e obtiveram valor médio de 6,18, inferior ao observado por Araújo (1996), que encontrou conversões alimentares de 8,82 para cordeiro Ideal; 7,41 para cordeiros mestiços (1/2 Texel $\times 1 / 2$ Ideal) e 7,8 para cordeiros (3/4 Texel $\times 1 / 2$ Ideal).

Os valores de conversão alimentar observados neste trabalho são explicados pela menor idade de abate dos animais, que determinou melhor eficiência de utilização do alimento. No entanto, estão aquém do esperado para animais dessa categoria em confinamento. Uma explicação seria a qualidade do feno utilizado no experimento.

O ganho de peso total do nascimento ao abate reflete o desenvolvimento geral do animal, desconsiderando a fase de bom desempenho durante a lactação e a de pior desempenho após o desmame. Os resultados deste estudo estão de acordo com os obtidos por Silva (1999), que observou ganho médio diário de 0,254 kg em cordeiros não-castrados do nascimento ao abate (aos 93,17 dias) e de 0,237 kg para os abatidos aos 119,19, em confinamento. Motta (2000) registrou ganho de $0,270 \mathrm{~kg}$ para machos abatidos ao $33 \mathrm{~kg}$ de PV com 91,95 dias de idade.

\section{Conclusões}

A suplementação com concentrado 30 dias antes do parto proporcionou às ovelhas melhor estado corporal ao parto e maior vigor aos cordeiros ao nascimento e não influenciou o desempenho dos cordeiros até o abate.

O desmame aos 45 dias de idade promoveu maior desenvolvimento durante o confinamento e, portanto, pode ser aplicado sem prejuízo quando houver incentivo à melhoria do sistema de produção.

\section{Literatura Citada}

ARAÚJO, J.R. Desempenho e características de carcaça de cordeiros de três grupos genéticos abatidos a mesma maturidade. Santa Maria: Universidade Federal de Santa Maria, 1996, 74p. Dissertação (Mestrado em Zootecnia) - Universidade Federal de Santa Maria, 1996.

BEETSON, B.R. Influence of plane of nutrition during late pregnancy and lactation on the survival and growth of Merino first cross lambs. In: LINDSAY, D.R. (Ed.) Reproduction in sheep. Canberra: Australian Academy of Science, 1984. p.213-215.

BENTO, A.H.L.; FIGUEIRO, P.R.P.; STILES, D.A. Efeitos da suplementação com subprodutos da lavoura de soja e da pastagem cultivada de azevém sobre a produção de ovelhas e crescimento de cordeiros da raça Corriedale. Ciência Rural, v.11, n.1, p.41-50, 1981 .

BOUCINHAS, C.C. Análise técnica e econômica de dois sistemas de alimentação de ovelhas manejadas para três 
partos a cada dois anos. Botucatu: Universidade Estadual Paulista, 2004, 66p. Dissertação (Mestrado em Zootecnia) Universidade Estadual Paulista, 2004.

CARVALHO, S. Desempenho, composição corporal e exigências nutricionais de cordeiros machos inteiros, machos castrados e fêmeas alimentados em confinamento. Santa Maria: Universidade Federal de Santa Maria, 1998. 100p. Dissertação (Mestrado em Zootecnia) Universidade Federal de Santa Maria, 1998.

CARVALHO, S.; PIRES, C.C.; BERNARDES, R.A.C. et al. Desempenho e produção de lã de ovelhas lactantes e ganho de peso e características da carcaça dos cordeiros. Ciência Rural, v.29, n.1, p.149-153, 1999.

CHESTNUTT, D.M. The effects of contracting silage offered in mid and late pregnancy on the performance of breeding ewes. Animal Production, v.49, p.453-444, 1989

GARCIA, I.F.F.; BONAGURIO, S.; PEREZ, J.R.O. Comercialização da carne ovina. In: ENCONTRO MINEIRO DE OVINOCULTURA, 1., 1998, Lavras. Anais... Lavras: Universidade Federal de Lavras, 2000. $177 p$.

GARCIA, I.F.F. Desempenho, características da carcaça, alometria dos cortes e tecidos e eficiência da energia, em cordeiros Santa Inês e Cruzas com texel, Ile de France e Bergamácia. Lavras: Universidade Federal de Lavras, 2001. 316p. Tese (Doutorado em Zootecnia) - Universidade Federal de Lavras, 2001.

GORDON, H.M.; WHITLOCK, H.V. A new technique for counting nematode eggs in sheep faeces. Journal Council Science Industry Research, v.12, p.50-52, 1939.

MAESTÁ, S.A. Desempenho produtivo, composição química e concentração de IgG do colostro e do leite de ovelhas e cordeiros de corte sob distintos níveis de proteína e energia. Botucatu: Universidade Estadual Paulista, 2003, 62p. Tese (Doutorado em Zootecnia) - Universidade Estadual Paulista, 2003.

MEDEIROS, G.R.; CARVALHO, F.F.R.; FERREIRA, M.A. Níveis de concentrado sobre o desempenho de ovinos Morada Nova em confinamento. In: REUNIÃO ANUAL DA SOCIEDADE BRASILEIRA DE ZOOTECNIA, 41., 2004, Campo Grande, Anais... Campo Grande: Sociedade Brasileira de Zootecnia, 2004. (CD-ROM).

MONTOSSI, F.; JULIÄN, R.S.; MATTOS, D. Alimentacion y manejo de la oveja de cria durante el ultimo tercio de gestacion em la region de basalto. In: SEMINARIO DE ACTUALIZACION EM TECNOLOGIAS PARA BASALTO, 1998, Tacuarembó. Anais... Tacuarembó: INIA, 1998. (Serie Técnica, 102).

MOTTA, O.S. Ganho de peso, características da carcaça de cordeiros (as) sob diferentes métodos de alimentação, pesos ao abate e produção de leite de ovelhas. Santa Maria: Universidade Federal de Santa Maria, 2000. 76p. Dissertação (Mestrado em Zootecnia) - Universidade Federal de Santa Maria, 2000.

NATIONAL RESEARCH COUNCIL - NRC. Nutrient requirements of domestic animals: nutrient requirements of sheep. Washington, D.C.: National Academy of Sciences, 1985. 99p.
ORSKOV, D.R. Nutricion protéica de los rumiantes. 2.ed. Zaragoza: Acríbia, 1988. 178p.

OTTO, C.; BONA, A.F.O.; SÁ, J.L. et al. Efeito do desmame aos 45 e 60 dias de idade no desenvolvimento de cordeiros. In: CONGRESSO BRASILEIRO DE MEDICINA VETERINÁRIA, 23., 1994, Olinda. Anais... Olinda: SBMV, 1994. v.28, p.401-405.

PILAR, R.C.; PIRES, C.C.; RESTLE, J. et al. Desempenho em confinamento e componentes do peso vivo de diferentes genótipos de ovinos abatidos aos 12 meses de idade. Ciência Rural, n.3, p.607-612, 1994.

PIRES, C.C.; SILVA, L.F.; SCHLICK, F.E. et al. Terminação de cordeiros em confinamento. Ciência Rural, v.30, n.5, p.875-880, 2000.

RAGLAND, K.K.T. Management systems for raising twin lambs. In: SHEPROFIT DAY, 1988, Kentucky. Proceedings... Kentucky: University of Kentucky, 1988. p.310-323.

RIBEIRO, L.A.O. Sobrevivência e desempenho de cordeiros do período perinatal ao desmame. In: PROGRAMA DE TREINAMENTO EM OVINOCULTURA, 1996, Porto Alegre. Anais... Porto Alegre: FARSUL/SENAR, 1996. 100p.

SAÑUDO, C.; SIERRA, I. Calidad de la canal y de la carne en la especie ovina. Ovino y caprino. Madrid: Consejo General De Colegios Veternarios, 1993. p.207-254.

STATISTICAL ANALYSIS SYSTEM - SAS. SAS user's guide: statistics. 5.ed. Cary: North Carolina, 1999. 956p.

SILVA, L.F. Crescimento, composição corporal e exigências nutricionais de cordeiros abatidos com diferentes pesos. Santa Maria: Universidade Federal de Santa Maria, 1999. 65p. Dissertação (Mestrado em Zootecnia) - Universidade Federal de Santa Maria, 1999.

SIQUEIRA, E.R.; AMARANTE, A.F.T.; FERNANDES, S. Estudo comparativo da recria de cordeiros em confinamento e pastagens. Revista de Veterinária e Zootecnia, v.5, p.17-28, 1993.

SIQUEIRA, E.R. Produção de carne de cordeiro. In: ENCONTRO MINEIRO DE OVINOCULTURA, 1., 1998, Lavras. Anais... Lavras: Universidade Federal de Lavras, 2000. p.145-156.

SUSIN, I.A.G.; BATISTA, A.M.; SIQUEIRA, E.R. Exigências nutricionais de ovinos e estratégias de alimentação. In: SILVA SOBRINHO, A.G.; BATISTA, A.M.V.; SIQUEIRA, E.R. et al. (Eds.) Nutrição de ovinos. Jaboticabal: FUNEP, 1996. 258p.

VILAS BÔAS, A.S.V. Idade a desmama e manejo alimentar na produção de cordeiros superprecoce. Botucatu: Faculdade de Medicina Veterinária e Zootecnia, 2001. 55p. Dissertação (Mestrado em Zootecnia), Universidade Estadual Paulista, 2001. 